\title{
An Analysis of the Anti-Japanese National United Front and Its Formation Process from the Perspective of Game Theory
}

\author{
Liu Zhao \& Huang Xiaoyi \\ Correspondence: Liu Zhao, Democratic Parties History Museum of China, NO. 35, Dongcun, JialingBridge, \\ Shangqingsi, Chongqing, China.
}

Received: April 8, 2021 Accepted: April 22, $2021 \quad$ Online Published: April 27, 2021

doi:10.11114/ijecs.v4i1.5225

URL: https://doi.org/10.11114/ijecs.v4i1.5225

\begin{abstract}
The united front is a magic weapon for the victory of the revolution, construction and reform of the Communist Party of China. The formation process of the united front is a kind of game, starting from the perspective of game theory, using the assets exclusiveness theory of economics, combining the Nash equilibrium and historical events, building a game model, analyzing the Anti-Japanese National United Front and its formation process, are of great significance to improve the scientific cognition level of historical research work and united front work.
\end{abstract}

Keywords: Game Theory, Anti-Japanese National United Front, Xi'an Incident, Nash Equilibrium

\section{The Anti-Japanese National United Front under the Vision of Game Theory}

The Anti-Japanese National United Front is the historical composition and practical application of the theory of the united front, and it is an important guarantee for the final victory of the anti-Japanese War. From the angle of game theory, the formation process of the anti-Japanese national united front is a game. During the Second World War, the thought method and research means of game theory were applied to the military field and other activities in wartime, which showed its important role. In 1944, Von-Neumann and Morgenstern co-authored the book "Game Theory and Economic Behavior", which marked the initial formation of game theory. According to Neumann and Morgenstern, game theory is the theory of using mathematical methods to study the optimal victory strategy of both parties in conflict of interest in competitive activities. The purpose of game theory is to show the players that they can find the best way from game theory if all rational participants want to win or maximize their returns. Therefore, game theory is called "countermeasure theory", which is a rational decision-making theory based on the analysis of numbers and logical reasoning. In addition, the game involves equilibrium, in which Nash equilibrium is regarded as a basic perspective of social practice and an important cornerstone for the study of social science. Nash equilibrium refers to the situation in which all players in a strategy combination are faced with such a situation that their strategy is the best when others do not change their strategy. In other words, if he changes his strategy at this point, his return will be reduced. Nash equilibrium is based on "game equilibrium", in which every rational player will not have the impulse to change strategy alone.

There are several reasons why the anti-Japanese national united front can be called a game:

1) The Anti-Japanese National United Front conforms to the purpose of game theory, it is the theory that the two sides (the CPC and the KMT) with conflict of interest make the optimal winning strategy in the competitive activities( the Civil War and the Anti-Japanese War). It points out a way to realize the maximization of profits for all rational players.

2) The Anti-Japanese National United Front conforms to the elements of game theory: the CPC and the KMT are the main players, both of them face the payoff matrix of power increase and decrease and national survival, and there are rules, information conditions, strategy, behavior order and game environment (the Japanese war of aggression against China) between them.

3) The Anti-Japanese National United Front has binding agreements: at the end of 1936, Chiang Kai-shek made three commitments, namely, "Stop exterminating the Communist Party of China, united the Red army against Japan, unified China, under his command", the Xi'an Incident was peacefully resolved, the civil war basically ended, and after the July 7 Incident, the CPC Central Committee sent the Declaration on Cooperation between the CPC and the KMT, which was issued by the KMT Central News Agency on September 22nd, marking the formal formation of the anti-Japanese national united front. These three commitments together with the Declaration on 
Cooperation between the CPC and the KMT, constitute binding agreements

To sum up, the Anti-Japanese National United Front is a game, and is a cooperative game. The difference between cooperative and non-cooperative games is whether there is binding agreements between the players who are interact with each other, the CPC and the KMT have made mutual commitments and issued the Declaration on Cooperation between the CPC and the KMT. Therefore, it is a cooperative game.

\section{Analysis of the Formation Process of the Anti-Japanese National United Front}

On the issue of the second cooperation between the CPC and the KMT, they each have two strategies, resulting in four pairs of strategy profiles: if the CPC is A, then the CPC's strategy profile is divided into cooperation a1 and non-cooperation a2; If the KMT is $\mathrm{B}$, its strategy profile is divided into cooperation a1 and non-cooperation b2. Combined with history, we can reasonably assume that the cooperative strategy will bring military strength +1 and political integration +1 to players $\mathrm{A}$ and $\mathrm{B}$, while the non-cooperative strategy will bring military strength -1 and political integration -1 to both sides.

Therefore, for players A and B, there are four pairs of strategy profile: a1b1, a1b2, a2b1, a2b2. See Table 1.

Table 1. Strategy Profiles on the Cooperation between PlayerA and PlayerB

\begin{tabular}{l|ll}
\hline \multicolumn{1}{c|}{ B } & $\mathrm{b}^{1}$ (cooperation) & $\mathrm{b}^{2}$ (non-cooperation) \\
\hline $\mathrm{a}^{1}$ (cooperation) & $\mathrm{a}^{1} \mathrm{~b}^{1}(+2 、+2)$ & $\mathrm{a}^{1} \mathrm{~b}^{2}(+1,-2)$ \\
$\mathrm{a}^{2}$ (non-cooperation) & $\mathrm{a}^{2} \mathrm{~b}^{1}(-2 、+1)$ & $\mathrm{a}^{2} \mathrm{~b}^{2}(-2 、-2)$ \\
\hline
\end{tabular}

Table 1 shows the strategy profile taken by the players and its effect.

1) If both the CPC and the KMT choose cooperation, the military strength and political integration of the two sides will increase simultaneously;

2) If the CPC choose cooperation, the KMT choose non-cooperation, only the political integration of the CPC will increase;

3) If the CPC choose non-cooperation, the KMT choose cooperation, only the political integration of the KMT will increase;

4) If both the CPC and the KMT choose non-cooperation, the military strength and political integration of the two sides will be damaged at the same time.

Given that the CPC is an advocate and proponent of the united front, there is no case of the CPC to choose non-cooperation; Similarly, since the KMT occupies the dominant political and military power, it will not actively cooperate with the CPC, thus ruling out the third strategy profile. Only the first, second and fourth strategy profiles are logical, the fourth is the CPC needs to take the initiative to be avoided, so does not meet the "order" element of the first choice of the CPC, only the first and second choice in line with the basic strategy of the CPC, and the first strategy profile is the game equilibrium that the CPC needs to promote.

It should be pointed out that as the party's united front strategy, the establishment of the "Anti-Japanese National United Front" within the party does not mean the establishment of the " Anti-Japanese National United Front " between the CPC and the KMT. Therefore, from the end of 1935 until the peaceful settlement of the Xi 'an Incident, the idea of the " Anti-Japanese National United Front " remained and could only be" anti-Chiang and anti-Japanese", its united objects were still only part of the left wings of the Kuomintang and part of the local powerful warlords, and no comprehensive consensus was reached with the KMT. That is, in the absence of specific conditions, the first strategy profile is difficult to achieve.

However, with the outbreak of the Xi 'an Incident, the number of players increased, namely, the Northeast Army and the 17th Route Army represented by Zhang Xueliang and Yang Hucheng. After the Xi 'an Incident, the CPC reached a consensus with Zhang and Yang that the goal was not to execute Chiang Kai-shek, but to "force Chiang to resist Japan". Therefore, the CPC and the forces of Zhang and Yang can be regarded as a player. At this time, in order to facilitate the game, we can regard the military strength, international assistance, political integration and so on of both sides as the exclusive assets of the company, the establishment of the Anti-Japanese National United Front as the establishment of joint ventures, the final victory of the Anti-Japanese War and the increase in the strength of the players as corporate income. According to the theory of assets exclusivity, the basis for the investors to participate in the income distribution of a joint venture is the "exclusivity" of their assets, the so-called "exclusivity" assets mean that without such assets, the benefits of the enterprise will be reduced, or even the enterprise will be disintegrated. The status of the investor of the joint venture depends on the irreplaceable degree of the assets it holds.

We regard the KMT as player C, and the CPC, who unite with Zhang and Yang as player D, as player D's military 
strength was combined and it detained player C's key asset ---Chiang Kai-shek. Therefore, player D has the key chip that affects the survival of player $\mathrm{C}$, which can force player $\mathrm{C}$ to choose the strategy of "cooperating to resist Japan ", thus realizing the game equilibrium.

In short, based on how to deal with Chiang Kai-shek, there are four groups of strategy profiles in the game of " cooperating to resist Japan ", as shown in Table2.

Table 2. Strategy Profiles on How to Deal with Chiang Kai-shek and Resist Japan

\begin{tabular}{|c|c|c|}
\hline $\mathrm{C} \quad \mathrm{D}$ & $\mathrm{d}^{1}$ (cooperation) & $\mathrm{d}^{2}$ (non-cooperation) \\
\hline $\begin{array}{l}\mathrm{c}^{1}(\text { cooperation }) \\
\mathrm{c}^{2}(\text { non-cooperation })\end{array}$ & $\begin{array}{l}\mathrm{c}^{1} \mathrm{~d}^{1} \\
\mathrm{c}^{2} \mathrm{~d}^{1}\end{array}$ & $\begin{array}{l}c^{1} d^{2} \\
c^{2} d^{2}\end{array}$ \\
\hline
\end{tabular}

Table 2 shows the combination of strategy profiles adopted by players and their effects:

First, if $\mathrm{C}$ chooses cooperation, D releases Chiang Kai-shek, the goal of "stopping the civil war, cooperating to resist Japan" will be achieved.

Second, if C chooses cooperation, D does not release Chiang Kai-shek, the goal of "stopping the civil war, cooperating to resist Japan " will not be achieved.

Third, if $\mathrm{C}$ chooses non-cooperation, D releases Chiang Kai-shek, the goal of stopping the civil war, cooperating to resist Japan " will not be achieved.

Fourth, if $\mathrm{C}$ chooses non-cooperation, D does not release Chiang Kai-shek, the goal of " stopping the civil war, cooperating to resist Japan " will not be achieved.

The second and third strategy profiles can be ruled out based on the motivation of player D. If the fourth scenario occurs -- Chiang Kai-shek is not released, Chiang's power will suffer a great loss, and there will be a power vacuum and chaos within the KMT, which will lead to a double-lose game. Therefore, c1d1 is the best strategy profile for players C and D.

\section{Conclusion}

To sum up, due to the change of the "exclusivity" of assets, the peaceful settlement of Xi 'an Incident and the game equilibrium reached by players $\mathrm{C}$ and $\mathrm{D}$, all of which promote player $\mathrm{A}$ and $\mathrm{B}$ reached a game equilibrium, the Declaration on Cooperation between the CPC and the KMT became a "rule" document, the two parties chose the cooperative game and the "benefits" of the players evolved into common interests. Finally, Nash equilibrium was reached, and the Anti-Japanese National United Front was established.

\section{References}

Chen, X. Q., \& Sun, J. (2006). The Basic Conditions of Establishing, Consolidating and Developing the United Front from Game Theory. Journal of Tongji University (Social Science Section), December, 2006.

John, K. F., \& Albert, F. (1986). The Cambridge History of China, 13. Republican China, 1912-1949, part 2, Cambridge University Press, 1986. https://doi.org/10.1017/CHOL9780521243384

John, K. F., \& Denis, T. (1983). The Cambridge History of China, 12. Republican China, 1912-1949, part 1, Cambridge University Press, 1983.

Nash, J. (1951). Two-person Cooperative Games. Econometrica, 21,128-140, 1953. https://doi.org/10.2307/1906951

Oppose Subjectivism and Sectarianism. (1941). The Speech at the Enlarged Meeting of the Political Bureau of the Central Committee of the Communist Party of China, September 10, 1941.

Selected Works of Mao Zedong. (1991). Selected Works of Mao Zedong, 2, 791. People's Publishing House, 1991.

Suzanne, P. (1999). Civil War in China: The Political Struggle, 1945-1949. Rowman \& Littlefield Publishers, 1999.

Von-Neumann, \& Morgenstern. (1947). Theory of Games and Economic Behavior. Princeton University Press, Princeton.

Yang, Q. S. (2020). A New Probe into the Xi'an Incident: The Mystery of Zhang Xueliang's Relationship with the Communist Party of China. Shaanxi People's Press, May 2020.

\section{Copyrights}

Copyright for this article is retained by the author(s), with first publication rights granted to the journal.

This is an open-access article distributed under the terms and conditions of the Creative Commons Attribution license (http://creativecommons.org/licenses/by/4.0/). 